\title{
THE PROFITABILITY OF GENERATION ENERGY COMPANIES DURING NINE YEARS
}

\author{
Felicetta Iovino ${ }^{1}$
}

DOI: https://doi.org/10.31410/ERAZ.S.P.2019.217

\begin{abstract}
The global financial crisis has affected all countries from 2008. Generation Energy companies play a strategic role in the economy of each country and determine the sustainability of the related resources involved. It is therefore interesting to analyze the profitability of generation energy companies, operating in particular during the generation phase, during the period of the crisis. The aim of this paper is to analyze the profitabilityoftheaforementioned companies, tocheckwhether they havesufferedtheeffectsoftheglobalcrisis. To this end, data from the AIDA database relating to Italian companies in the sector were used. The profitability of these companies has been analyzed using the main profitability, ROA and ROE ratios. An analysis of the trends of these indices was carried out for the period 2008-2017. In this way, it has been verified whether the global crisis has affected the profitability of generation energy companies in Italy.
\end{abstract}

Keywords: Crisis, Energy, ROA, ROE, Profitability, Performance, Ratio.

\section{INTRODUCTION}

$\mathrm{T}$

his paper analyses the profitability situation in Italy with specific reference to generation energy companies. In particular, it aims to analyse the profitability structure of Italian generation energy companies during and after the 2008 crisis, with regards to the three Italian geographic zones and the two business energy markets, electricity and gas. To this end, three key research questions have been posed:

1. What is the present situation and what the trend has been from 2008-2017 in the three Italian geographic zones and in the analysed business markets?

2. Are there differences among the analysed business markets or geographic zones?

3. Are these eventual differences significant from a statistical point of view?

The hypotheses are that $\left(\mathrm{H}_{1}\right)$ the global economic crisis did not significantly affect the profitability structure of generation energy companies, by means of its resilience ([1] - [2] - [3] - [4] $-[5]) ;\left(\mathrm{H}_{2}\right)$ there are differences among groups that are belonging to diverse business markets or geographic zones; $\left(\mathrm{H}_{3}\right)$ the above differences are statistically significant. For that aim, the profitability structure is assessed using two indices: ROA (operating income /total assets) and ROE (net income/equity); the years considered are ten, that is from 2008 to 2017; a trend analysis and ANOVA (one way) have been carried out.

In the following paragraphs literature notes on energy companies are presented. Then the methodology, results and implications are illustrated.

\section{LITERATURE NOTES}

The resilience of energy companies has been subject of analysis for different authors ([6] - [7] - [8]).

University of Sannio, Benevento, Italy 
[6] provides useful insights to new US government that can consent to achieve various energy's goals, in particular to include stability and resilience in the US energy policy. Among those recommendations policy correction and not a total change move US energy companies towards certainty and more predictable investment climate.

[7]'s study highlights the use of microgrids to give resilience to all energy systems. Positive impacts on demand reduction and costs of energy companies are the main reasons of its employ.

[8] suggest a distributed energy management algorithm to improve the resilience of the energy companies. In fact, that algorithm protects against malicious cyber-attacks and its negative results on the economic balancing of energy system.

[9] proposes a model by the UK's wind capabilities. It highlights financial evidences that can increase resilience of energy system.

[10] provide a framework for an e-voucher mechanism that gives economic advantages for customers, but also for energy companies by means of decreasing costs and increasing its resilience.

[11] suggest useful highlights in relation to energy price inflation as an index for assessing macro-financial effects on energy companies.

[12]'s study (2017) proposes a price-forecasting model that has economic and financial positive effects for both energy system and customers.

$[1]-[2]-[3]$ and $([13]-[14]-[15]-[16]-[17]-[18]-[19])$ provide interesting insights about energy companies' performance. Those studies suggest the main role of relationships with customers and sizes to raise companies' performance.

[20] proposes a multi-factor asset pricing model to evaluate the grow rates of renewable energy companies.

[21] analyses the central variables that affect energy companies' performance. That paper focuses in particular on Russian and US companies. That study finds that regional variables and financial indices have an important impact for both Russian and US companies' performance.

[22] suggests useful highlights about the implementation of a program of efficient lamps on energy companies' costs. In fact, the study finds that it has a more important impact than the price of electricity on financial performance.

[23]'s study (2015) analyses a relation among financial development, economic growth and Co2 emissions. The main findings are that trade openness and financial development are interrelated.

\section{RESEARCH METHODOLOGY}

\subsection{Data collection and sample characteristics}

Secondary data have been collected from AIDA database. To assess the profitability structure, two ratios, ROA (operating income/ total assets) and ROE (net income/equity), have been selected. The last ten years after liberalization, i.e. 2008-2017 had been chosen. The final sample 
was composed of the generation energy companies, that is 426 generation energy firms. Then, various groups have been made using two discriminating variables, the geographic zone and the belonging business market. Three clusters have been identified in relation to the different geographic areas: north, centre and south, following the conventional classification of Italian regions. According the geographical area, the sample was distributed as following: $67 \%$ in the North group, $16 \%$ in the Centre and $17 \%$ in the South ones. The belonging market has been identified using a specific section for every energy company using the statistical classification of economic activities in Italy (ATECO codes). In this way, two groups have been found: gas market and electricity market.

Following the second variable, the sample was made up of $98 \%$ energy generation in electricity market and $2 \%$ energy companies belonging to gas market.

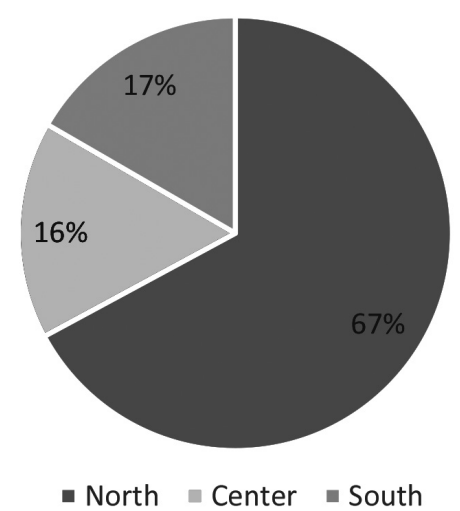

Figure 1: Geographic localization of Italian generation companies, source: our elaboration

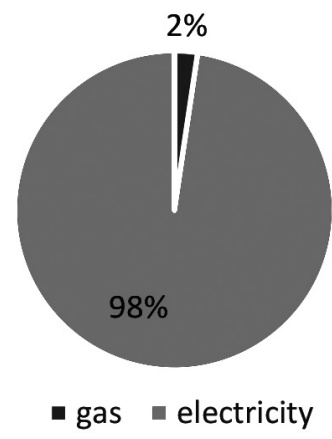

Figure 2: market distribution of Italian generation companies, source: our elaboration

\subsection{Method}

First of a trend analysis has been performed for the period 2008/2017 for every index and group. Therefore, analysis of variance (ANOVA one-way) has been employed to evaluate the differences of means among groups and the response variable means at the different variable levels. The null hypothesis states that all population means (factor level means) are equal while the alternative hypothesis states that at least one is different. For our analysis, the independent variables were the various geographic localization and the different business market while the dependent variables were the indices. ANOVA one-way type has been chosen because the two variables were analysed separately. 


\section{RESULTS AND DISCUSSION}

\subsection{Trend analysis}

ROA (operating income / total assets) expresses the extent to which the total investments made in all types of management of the company are renumbered by the operating activity, i.e. the core of the business. It is evident that this profitability index should be evaluated together with other profitability indexes to verify if the company is profitable or not precisely in terms of profitability. In this sense, once the value of this index is higher, it is the income situation of the company. During the 10 years analyzed, this index assumes values between -0.07 and 10.13 if geographical location is taken into account and instead between 2.683 and 8.745 if the belonging business is taken into consideration. Figures n. 3 and n. 4 show how the value of this index tends to grow over the 10 years taking on very positive values. This occurs in every geographical location analyzed and also in both businesses in which the energy business is distinguished. The ROA takes on the highest value in 2017 if we refer to the geographical location, when the crisis is now far away. During the previous years there was a substantial growth trend in all geographical areas. However, companies in the north experienced a decrease between 2014 and 2016. In the same sense, the companies of the center recorded a decrease starting from 2013. The most profitable companies appeared the northern companies, although outdated by companies from 2015 of the South. From a business point of view, electricity companies appear to be the most profitable in the 2008-2015 period. Starting from this last year they are outdated by the gas companies.

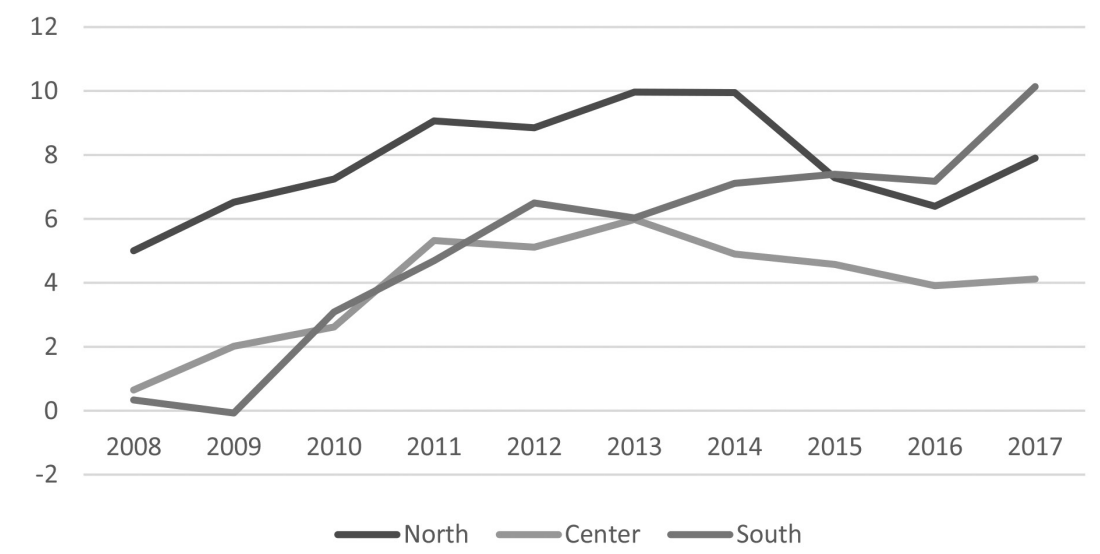

Figure 3: Trend of $R O A$ according to geographic localization, Source: our elaboration

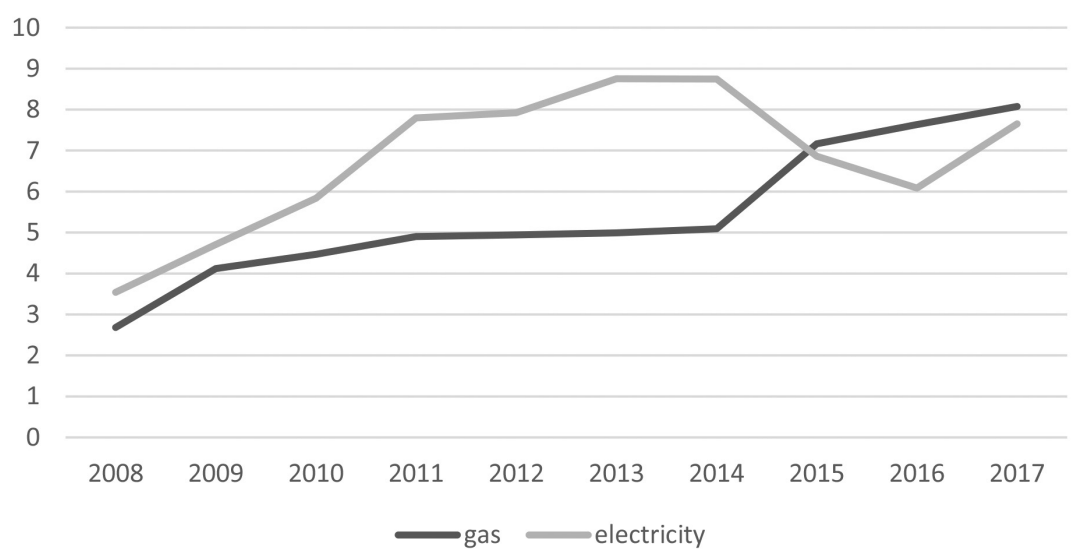

Figure 4: Trend of $R O A$ according to market, Source: our elaboration 
ROE (net income / equity) is the profitability index that expresses the overall profitability of the company. It is therefore the profitability that is produced by the company taking into account all the revenues and income and costs and charges deriving from all the management of the company. It is therefore a summary indicator that is very important also for the shareholders, because on the basis of the net profitability the dividend assigned to them will be determined. In order to verify the company as the ROA it is necessary to analyze it together with other profitability indexes, but also other financial indexes including leverage. In fact, in the latter case, the possibility of procedures for the stipulation of further loans that may allow the company to expand further while maintaining a profitability of positive equity is verified. As with all profitability ratios, it is appropriate that this value takes positive values and as high as possible. Over the years, the profitability of equity appears to be quite variable. If we consider the geographical location the ROE assumes a negative value in 2009, equal to -3.06 in the southern regions, while it assumes the maximum value in 2012 equal to 20.98. The trends appear to be increasing in all regions up to 2011, except for a decrease in the south in 2009. Starting in 2001 in all regions there was a new decrease until 2015. After that date, the ROE values rose again in two of the Italian geographical areas (fig. 5).

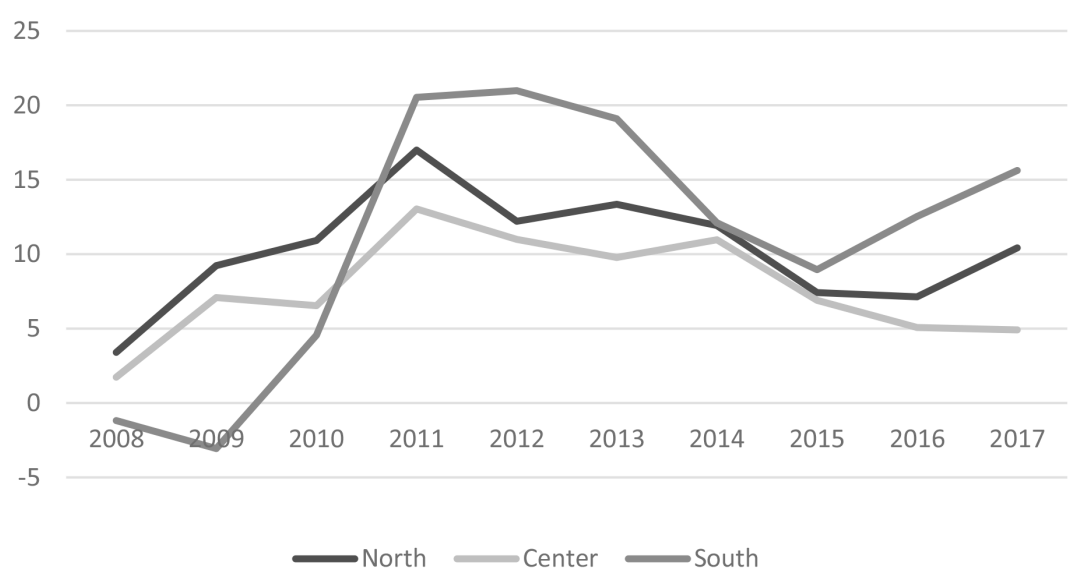

Figure 5: Trend of $R O E$ according to geographic localization, Source: our elaboration

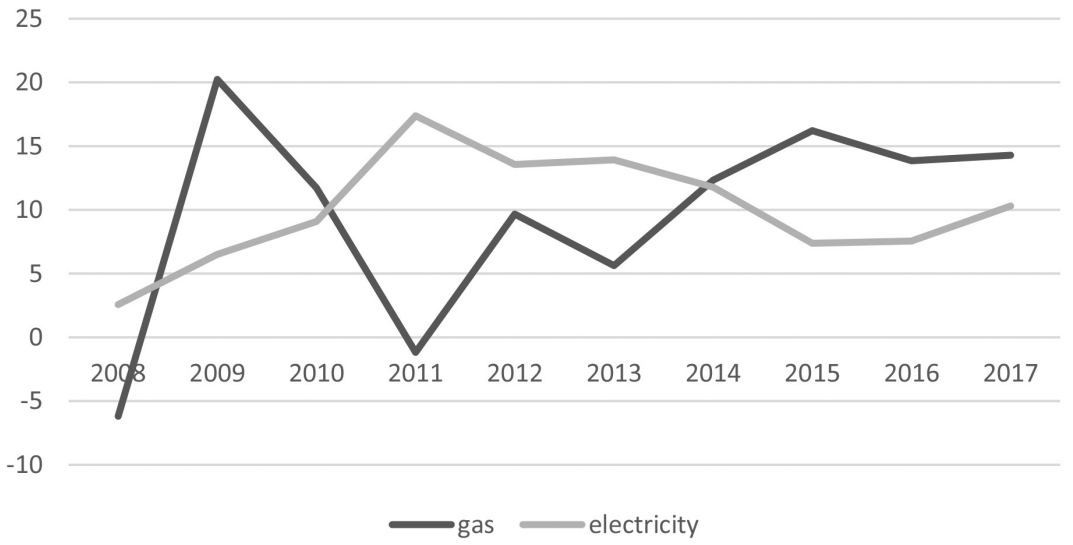

Figure 6: Trend of $R O E$ according to market, Source: our elaboration

If we consider the geographical location (fig. 6) the ROE trend appears to be very variable over time for the gas business, while it is more stable for the electricity business. The minimum value is reached in 2008 and is equal to -6.18 , while the maximum value is reached in 2009 and is equal to 20.35. After a very low value in 2008 , the gas business recorded a considerable increase in 2009 and then decreased significantly in 2011. In the following years the general trend was increasing. Even the electricity business is growing until 2011 and then decreasing until 2015 
and growing again in the following two years. The profitability of own capital although some rather critical value appears to be good over the ten years analyzed. The trend in ROA both from a geographical point of view and from a business point of view over the 10 years analyzed appears to be increasing. Therefore, this index is not affected by the crisis. The ROE trend appears much more variable both with reference to the different geographical areas and with reference to the two businesses. The gas trend appears more variable in this index and therefore more affected in its overall profitability. This is probably due to the greater infrastructural weight that characterizes the gas business. In fact, they affect the determination of the net income measure. Therefore, we can affirm that the H1 hypothesis is confirmed, because companies have not been conditioned by the crisis. The $\mathrm{H} 2$ hypothesis appears to be substantially validated, because there are differences between the different geographical areas and the two different businesses.

\subsection{Analysis of variance}

About ROA, Table 1 highlights the results of the analysis having the geographic location as the discriminating variable. There is a statistically significant difference between groups $(F(2,27)=$ $7.350661, p=0.002827)$, in fact $\mathrm{F}>\mathrm{F}$ crit $(\mathrm{p}$ value $<0.05)$.

Table 1: $\boldsymbol{R O A}$ - Analysis of variance with geographical localization as independent variable

\begin{tabular}{|l|r|r|r|r|r|r|}
\hline Source of Variation & \multicolumn{1}{|c|}{ SS } & $d f$ & $M S$ & $F$ & $P$-value & $F$ crit \\
\hline Between Groups & 78.62691 & 2 & 39.31346 & 7.350661 & 0.002827 & 3.354131 \\
\hline Within Groups & 144.4038 & 27 & 5.348289 & & & \\
\hline Total & 223.0307 & 29 & & & & \\
\hline Sigifing
\end{tabular}

Significant level at 0,05

The null hypothesis must therefore be rejected and the alternative hypotheses acetate. There is therefore at least one value different from the others within the analyzed sample. If, on the other hand, we consider the business of belonging as a discriminating factor (Table 2) there is instead no statistically significant difference. The null hypothesis must be accepted and those alternatives rejected. In fact, $F(1,18)=3.254333, p=0.087997$, in fact $F<F$ crit, $p$ value $>0.05$ ).

Table 2: $\boldsymbol{R O A}$ - Analysis of variance with belonging sector as independent variable

\begin{tabular}{|l|c|r|r|r|r|c|}
\hline Source of Variation & \multicolumn{1}{|c|}{$S S$} & $d f$ & $M S$ & $F$ & $P$-value & F crit \\
\hline Between Groups & 9.560466 & 1 & 9.560466 & 3.254333 & 0.087997 & 4.413873419 \\
\hline Within Groups & 52.87978 & 18 & 2.937766 & & & \\
\hline Total & 62.44025 & 19 & & & & \\
\hline
\end{tabular}

Significant level at 0,05

The ANOVA (one-way) applied to the ROE shows that there is no significant difference when the geographical location is considered as a discriminating variable. The null hypothesis must be accepted and the alternative hypotheses rejected (table n. 3). The same applies to the case as the discriminating business is considered as a variable. Also, in this case (table n. 4) there is no statistically significant difference between the values of the two businesses analyzed.

Table 3: ROE- Analysis of variance with geographical localization as independent variable

\begin{tabular}{|l|r|r|r|r|r|c|}
\hline \multicolumn{1}{|c|}{ Source of Variation } & \multicolumn{1}{c|}{ SS } & $d f$ & $M S$ & $F$ & P-value & $F$ crit \\
\hline Between Groups & 60.74579 & 2 & 30.37289 & 0.902983 & 0.417252 & 3.354131 \\
\hline Within Groups & 908.1772 & 27 & 33.63619 & & & \\
\hline Total & 968.923 & 29 & & & & \\
\hline
\end{tabular}

Significant level at 0,05 
Table 4: ROE - Analysis of variance with belonging market as independent variable

\begin{tabular}{|l|c|r|r|c|c|c|}
\hline Source of Variation & \multicolumn{1}{|c|}{ SS } & $d f$ & $M S$ & $F$ & $P$-value & $F$ crit \\
\hline Between Groups & 0.606727 & 1 & 0.606727 & 0.014433 & 0.905705 & 4.413873 \\
\hline Within Groups & 756.6657 & 18 & 42.03698 & & & \\
\hline & & & & & & \\
\hline Total & 757.2724 & 19 & & & & \\
\hline
\end{tabular}

Significant level at 0,05

The results of the ANOVA (one-way) show therefore that the H3 hypothesis is not substantially verified. The existing differences are not statistically significant. This applies both to the geographical location and to the business in question in the case of ROE. However, in the case of ROA this is valid only in the case of the business to which it belongs. In fact, in the case of geographical location, significant differences are evidenced from a statistical point of view.

\section{CONCLUSION}

In conclusion we can say that the hypotheses could have been almost confirmed. In fact, with regard to ROA, the trend appears to be growing both for the businesses analyzed and for the different geographical areas. Therefore, it does not appear to be conditioned by the crisis. Furthermore, there are differences in the trend both from the point of view of geographical location and for businesses. However, these differences are statistically significant only from the geographical point of view. From ROE point of view, gas companies appear to be affected by the crisis compared to electricity companies. ROE does not appear affected by the crisis instead, if we refer to the geographical location. In addition, from the statistical point of view the differences highlighted in the trend especially with regard to the distinction between the two businesses do not appear to be statistically significant. The results therefore highlight the limits of the study. In fact, there is only the analysis of the companies that survived the crisis and therefore the most profitable ones over time. Furthermore, only two profitability ratios were considered. Therefore, for an overall analysis it is opportune to take into consideration a plurality of indices, including financial ones, in order to be able to give a broader and overall judgment on this type of company. These are therefore the future research lines. Added to these is the opportunity to carry out comparisons between energy production companies at least with reference to European countries $([4]-[5]-[16])$.

\section{REFERENCES}

[1] Iovino, F. (2012) Le scelte delle politiche di marketing delle imprese energetiche, Management delle utilities, 4, 23-35.

[2] Iovino, F. (2014) L'internet marketing nelle imprese energetiche: il caso di un'impresa elettrica romana, Mercati e competitività, 3, 141-161.

[3] Iovino, F. (2015) Relationship marketing by Energy companies, Review of International comparative management, 16(5), 558-573.

[4] Iovino, F., (in press, a) The profitability of water companies during ten years, in Conference Proceedings: 3rd International Scientific Conference on Economics and Management -EMAN 2019: Economics \& Management: How to Cope With Disrupted Times, Ljubljana, Slovenia, March 28th, Printed by: All in One Print Center, Belgrade.

[5] Iovino, F., Migliaccio, G. (2019) Energy companies and sizes: An opportunity? Some empirical evidences, Energy Policy, Vol. 128, May 2019, DOI: 10.1016/j.enpol.2019.01.027, 431-439. 
[6] Gattie, D.K. (2017) Incorporating stability and resilience in energy policy for the U.S. power sector: recommendations for the Trump administration, The Electricity Journal, Vol. 30, No.1, pp. 47-54.

[7] Xiaonan L., Jianhui W. and Liping, G. (2016) Using microgrids to enhance energy security and resilience, The Electricity journal, Vol. 29, No. 10, pp. 8-15.

[8] Zeng, W., Zhang, Y. and Chow, M. (2017) Resilient distributed energy management subject to unexpected misbehaving generation units, IEE transaction on industrial informatics, Vol. 13, No.1, pp. 208-216.

[9] Hdidouan, D. and Staffell, I. (2017) The impact of climate change on the levelised cost of wind energy, Renewable energy, Vol. 101, pp. 575-592.

[10] Chen, T., Pourbabak, H., Liang, Z. and Wencong, S. (2017) An integrated evoucher mechanism for flexible loads in real time retail electricity market, IEE ACCESS, Vol. 5, pp. 2101-2110.

[11] Breiteinfeller, A., Crespo Cuaresma, J. and Mayer, P. (2015) Energy inflation and house price corrections, Energy economics, Vol. 48, pp. 109-116.

[12] Neupane, B., Woon, W. and Aung, Z. (2017) Ensemble prediction model with expert selection for electricity prices forecasting, Energies, Vol. 10, No. 1, pp. 77.

[13] Iovino, F., Migliaccio, G. (2016) E-marketing by energy companies. 9th Annual Conference of the Euromed Academy of Business, "Innovation, Entrepreneurship and Digital Ecosystems", 14-16 September 2016, Warsaw, Poland, Book of Conference Proceedings, Euromed Press, 1036-1048.

[14] Iovino, F., Migliaccio, G. (2018a) Profitability dynamics of tourism companies during the crisis period (2007-2015), in Vrontis D., Weber Y., Tsoukatos E. (Eds), Conference readings book proceedings, 11th Annual Conference of the EuroMed: Research Advancements in National and Global Business. Theory and Practice, Valletta, Malta,September 12th14th, EuroMed Press: Cyprus, 663-677.

[15] Iovino, F., Migliaccio, G. (2018b) Financial dynamics of tourism companies, travel agencies and tour operators, during the crisis period, in Conference Proceedings: 2nd International Scientific Conference on Economics and Management -EMAN 2018: Economics \& Management: How to Cope With Disrupted Times, Ljubljana, Slovenia, March 22th, Printed by: All in One Print Center, Belgrade, 693-702.

[16] Iovino, F., Migliaccio, G. (2019, b) Financial Dynamics of Energy Companies During Global Economic Crisis, International Journal of Business and Globalisation, Vol. 22, n. 4, pp. 541-554. (doi: 10.1504/IJBG.2019.10011698).

[17] Iovino, F., Migliaccio, G., (in press, a) Mobile marketing and strategy by energy companies, International journal of Public Sector and Performance Management.

[18] Iovino, F., and Migliaccio, G., (2019) E-marketing and strategies by energy companies, in Weber, Y., Vrontis, D., Shams, R., Manos, R., "The Cross-disciplinary perspectives of Management Ambidexterity: Challenges and Opportunities", Cross-disciplinary Management Perspectives: Applications, challenges and opportunities Series, Vol. 1, Emerald Publishing, ISBN: 9781838672508.

[19] Iovino, F., (2019), The Financial Sustainability of Water Companies: The Italian Case, 42nd International Scientific Conference on Economic and Social Development, ESD 2019, London, UK, 12-13 June, 2019, in Book of Proceedings, Editors: Dukic, G., Clifford, J., Atkinson, D., ESD 2019, London, UK, 12-13 June, 2019, Varazdin Development an Entrepreneurship Agency, Varazdin, Croatia/Pearson College London, London, /UK/ University North, Koprivnica, Croatia/ Faculty of Management University of Warsaw, Warsaw, Poland/ Faculty of Law, Economics and Social Sciences Sale - Mohammed V University in Rabat, Morocco, ISSN: 1849-6903. 
[20] Inchauspe, J., Ripple, R.D. and Trueck, S. (2015) The dynamics of returns on renewable energy companies: A state-space approach, Energy economics, Vol. 48, pp. 325-335.

[21] Meltenisove, E. (2013) Power generation companies' performance in liberalized electricity market: cross country analysis, in Filipovic, D. and Urnaut, A.G., 2nd International Scientific Conference on Economic and Social Development (ESD), Paris, France, pp. 1132-1141.

[22] Mills, E. (1993) Efficient lighting programs in Europe - cost-effectiveness, consumer response, and market dynamics, Energy, Vol. 18, No. 2, pp. 131-144.

[23] Omri A., Daly S., Rault C. and Chaibi A. (2015) Financial development, environmental quality, trade and economic growth: what causes what in MENA countries, Energy economics, Vol. 48, pp. 242-252. 